\title{
Immunophenotypic Complete Response
}

National Cancer Institute

\section{Source}

National Cancer Institute. Immunophenotypic Complete Response. NCI Thesaurus. Code C123588.

The disappearance of all signs of cancer, supported by the absence of phenotypically aberrant plasma cells (clonal) in bone marrow. (Rajkumar SV, Harousseau J, Durie B et al, Consensus recommendations for the uniform reporting of clinical trials: report of the International Myeloma Workshop Consensus Panel 1. Blood. 2011; 117(18):4691-4695) 